\title{
The Spectrum of Congenital Heart Diseases in Robinow Syndrome
}

\author{
$J_{\text {AMEEL }}$ AL-A Ata, FRCP(C)*, MARC PAQUET, FRCP(C)*, \\ and AHMED S. AL-TEEBI, FRCP(ED)*** \\ Division of Pediatric Cardiology * and Division ofMedical Genetics**, \\ The Montreal Children's Hospital, Montreal, Quebec, Canada
}

\begin{abstract}
We present the case of a newborn infant with classical signs of Robinow Syndrome and major congenital cardiac malformations consisting of double outlet right ventricle with subaortic VSD, infundibular and valvular stenosis, and patent ductus arteriosus. Similar patients of Robinow Syndrome with cardiac involvement are briefly reviewed from the literature and the importance of recognizing heart defects in early life is stressed.
\end{abstract}

Keywords: Right ventricle, Robinow Syndrome, CongenitaJ, Patent ductus arteriosus, Ventricular septal defect, Pulmonary atresia, Double outlet, Right ventricle, Autosomal inheritance.

\section{Introduction}

Robinow Syndrome is a rare genetic disorder associated with fetal face appearance and genital hypoplasia with or without limb shortness. It exists as both autosomal dominant and autosomal recessive forms!1,2]. Cardiac malformations have been described in patients with Robinow Syndrome'<', but no specific pattern has been identified. Previously reported cases include ASD[4], Tetralogy of Fallot[5], coarctation of the aorta and bicuspid aortic valve[6], severe valvular pulmonary stenosis with VSO[7], pulmonary atresia with intact ventricular septum, isolated $\mathrm{POA}[8]$, and tricuspid atresia[3]. In the present report we describe a case of Robinow Syndrome with associated double outlet right ventricle (DORV), subaortic VSD, infundibular and valvular pulmonary stenosis, and a POSe Such cardiac anomaly has not been recognized before in patients with Robinow Syndrome.

Correspondence \& reprint requests to: Dr. J. Al-Ata, Division of Pediatric CardioJogy, Room C-352, The Montreal Children's Hospital, 2300 Tupper Street. Montreal.Que H3H IP3, Canada. Accepted for publication: 23 February 1998. Received: 07 October 1997. 
Case report: The patient was a male infant born at full term to a healthy GZpoA I mother by spontaneous 'vaginal delivery. He was noted to have dysmorphic features and cyanosis with minimal respiratory distress in the first few hours of life. His parents were phenotypically normal and were of southeastern Asian origin. They were nonconsanguineous and their family history was unremarkable. Examination showed a relatively large head with frontal bossing and fetal face appearance, wide palpebral fissures and prominent eyes, depressed nasal bridge with short nose, anteverted nares and long philtrum, triangular mouth with thick alveolar ridge and narrow palate, posteriorly angulated ears and fleshy ear lobules. Both upper and lower extremities were relatively short with a meso-rhizemelic appearance (Fig.I). His penis and scrotum were underdeveloped.
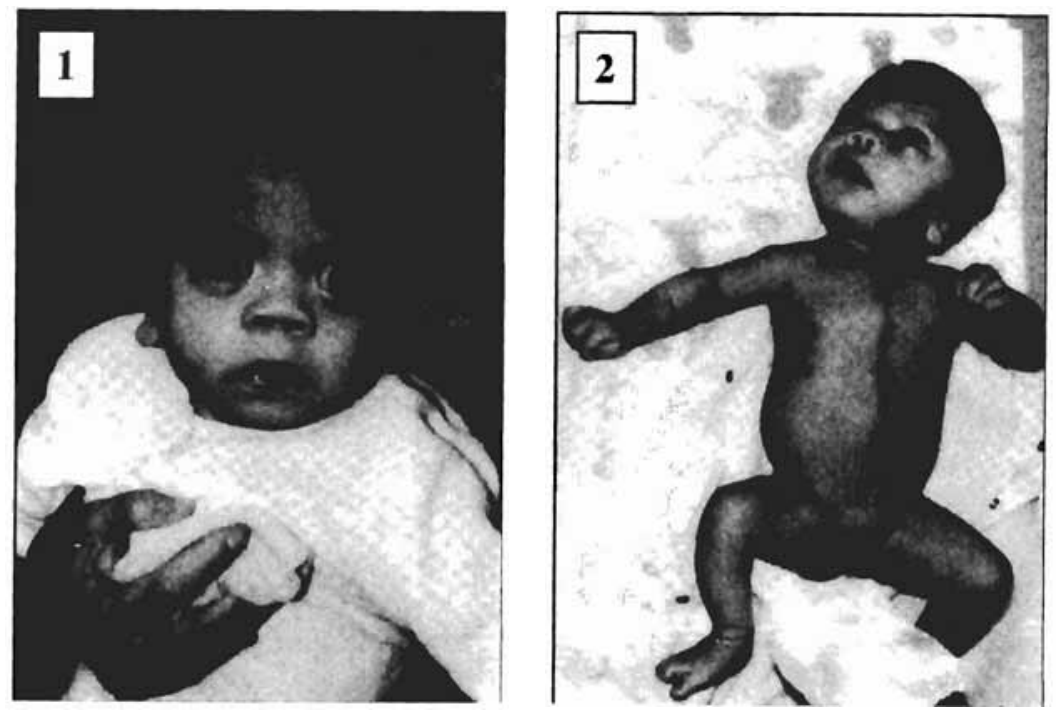

FIG. I. Plate I: Photograph of the patient demonstrating typical fetal face appearance with frontal bossing and prominent eyes

Plate Z: Note relatively short upper and lower limbs and the under-developed external genitalia (the midline sternotomy scar is also noted)

Cardiovascular examination revealed (HR 120 BPM, BP 68/44 mmHg) equal yet slightly weak pulses in all four limbs, a hyperactive RV impulse, and thrill in the left upper sternal border. Auscultation revealed a normal SI' a single loud Sz, and a grade 4/ 6 harsh ejection systolic murmur heart with maximal intensity at 2 nd left intercostal space near the sternal border; diastole was clear. The chest was clear to auscultation and no organomegaly was detected on abdominal examination. The chest $\mathrm{x}$-ray revealed abdominal situs solitus, levo-cardiac with boot-shaped cardiac silhouette left aortic arch and small lung volumes. The electrocardiogram showed sinus rhythm, absence of normal R-wave transition on the precordial leads with absent Q-wave in V6 suggesting right ventricular hypertrophy. Two-dimensional echocardiography revealed atrial situs 
solitus, normal systemic and pulmonary venous drainage, secundum atrial septal defect. DORV with single anterior malalignment ventricular septal defect, severe infundibular and valvular pulmonary stenosis. proximal left pulmonary artery stenosis and a PDA (Fig. 2). Right and left cardiac cauterization confirmed the diagnosis.

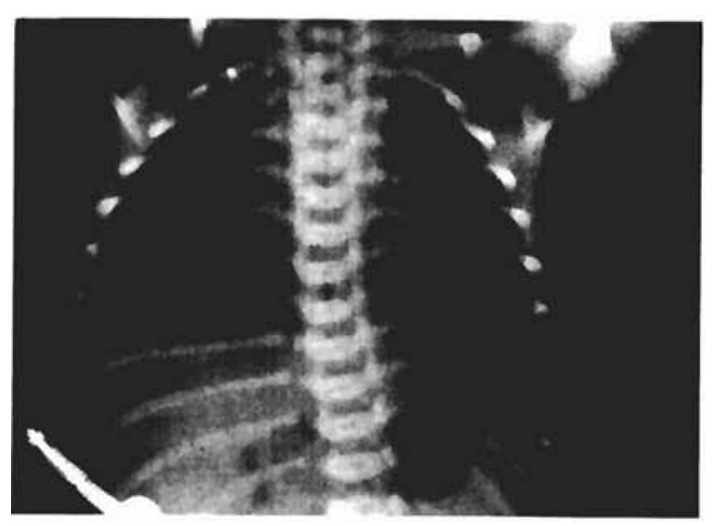

Fili. 2. A stilframe from a two-dimensional echocardiogram in the apical 4 chamber view with the transducer pointing anteriorly and superiorly. demonstrating the origin of both great arteries from the right ventricle.

$(\mathrm{Ao}=$ aorta. $\mathrm{PA}=$ pulmonary artery, $\mathrm{LPA}=$ left pulmonary artery. $\mathrm{RV}=$ right ventricle. $\mathrm{RPA}=$ right pulmonary artery)

Clinical course: On the second day of life he presented with several hypercyanotic spells not responsive to $1 . \mathrm{V}$. morphine nor $1 . \mathrm{V}$. propranolol. He was finally stabilized on a prostaglandin (POE) drip to maintain ductal patency ensuring good pulmonary blood flow. On day 5 of life he underwent primary intraventricular tunnel repair of the DORV with resection of the infundibular and pulmonic stenosis. enlargement of the right ventricular outflow tract and main pulmonary artery with a pericardial transannular patch, repair of the LPA stenosis. PDA division. and partial closure of the scandium ASD. He was discharged home after an uneventful postoperative period on maintenance with digoxin and was doing well and gaining weight.

\section{Discussion}

Cardiac malformations are a relatively common component of Robinow Syndrome [9.31. Of the 75 published cases. ten cases (13\%). including ours, have some form of cardiac malformations, It seems that patients with Robinow Syndrome and DORV described in the literature and that other forms of congenital heart disease sharing the same embryological origin (i.e. the failure to achieve normal conotruncal rotation) like other transposition of the great arteries complexes, can be theoretically expected in patients with Robinow Syndrome[IO.111. This indicates that cardiac malformations associated with Robinow Syndrome are diverse and can be life-threatening. especially in the early neonatal period. Finally. the easily-recognizable specific phenotype is an excellent diagnostic guide to early recognition of such potentially serious congenital heart 
malformations and, thus, all patients with suspected Robinow Syndrome should be referred to a Pediatric Cardiologist, preferably one who is in a tertiary pediatric center where intensive care and cardiothoracic surgery expertise is available.

\section{References}

[I] Robinow M. The Robinow (fetal face) Syndrome, a continuing puzzle. Clin Dysmorphol 1993; 2: 189198.

[2] Teebi AS. Autosomal recessive Robinow Syndrome.Am J Med Genet 1990; 35: 64-68.

[3] Atalay S, Ege B, Imamoglu A, Suskan E, Ocal B, Gumus H. Congenital heart disease and Robinow syndrome. Clin Dysmorphol 1993; 2(3): 208-210.

[4] Protnoy Y. Robinow Syndrome.CU« Pediatr 1979; 18: 707-708.

[5] Bain MD, Winter RM, Burn J. Robinow Syndrome without mesomelic brachymelia. A report of five cases. J Med Genet 1986; 23:350-354.

[6] Butler MG, Wadlington WB. Robinow Syndrome: report of two patients and review of literature. Clin Genet 1987; 31(2): 77-85.

[7] Jewett T, Hoyme HE. Fetal face, cleft palate and digital anomalies with normal stature and associated heart defects. Further delineation of the Robinow Syndromeor a distinct entity? Proc Greenwood Genet 1989; 8: 203-204.

[8] Wiens SL, Strickland DK, Snifen B, Warady BA. Robinow Syndrome: report of two patients with kidney disease. Clin Genet 1990; 37-: 481-484.

[9] Webber SA, Wargowski DS, Chitayat D, Sander EG. Congenital heart disease and Robinow Syndrome: coincidence or additional component of the syndrome?Am J Med Genet 1990; 37: 519-521

[10] Good DA, Edward JE. The spectrum of TGA with specific reference to developmental anatomy of the conus. CIRC 1973; 48: 406.

[11] Anderson RH, Wilkinson JL, Arnold R, Becker AE, Lubkiewicz K. Morphogenesis of bulboventricular malformations. II. Observations on malformed hearts. Br Heart J 1974; 36(10): 948-970.

Not mentioned in the main text:

[4] Balci S, Ercal MD, Say B, Turner M, Orah O, Sarinaylar S. Robinow Syndrome: fourteen cases with special emphasis on dermatoglyphics and hand malformation (split hand). Clin Dysmorphol 1993; 2: $199-207$

[8] Kelly TE, Benson R, Temtamy, Plotnick L, Levin S. The Robinow Syndrome with a detailed study of the phenotype. Am J Dis Child 1975; 129: 383-386

[9] Pfeiffer RA, Muller H. [Complex of multiple malformations in two unrelated children (author's transli]. Padiatr Padol 1971; 6(3): 262-267. 
مـدى الأمـــاض القلبيـة الخلقيـة في متـلازمـة روبينـو

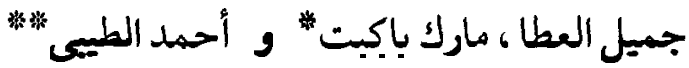 \\ * ثعبة أمراض قلب الأطفال ، و** شعبة الوارثة الطبية ، مستشفى منتريال للأطفال ،

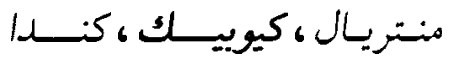

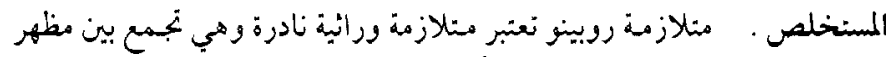

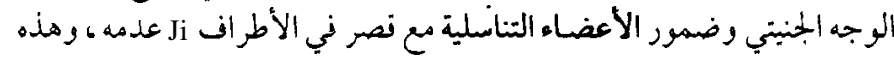

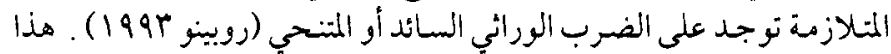

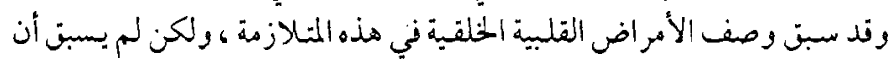

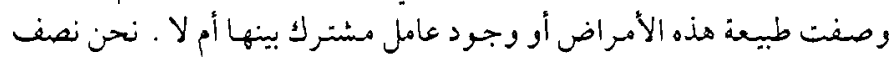

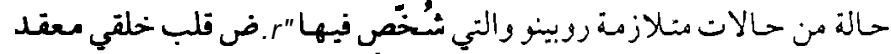

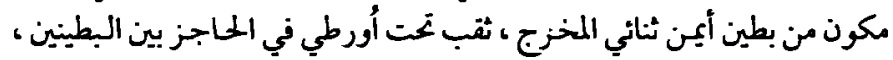

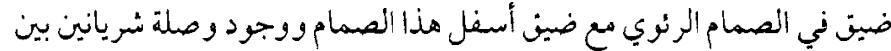

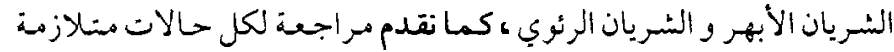

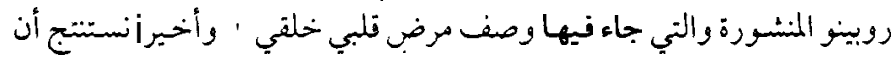

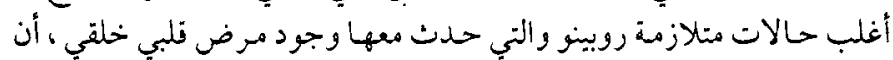

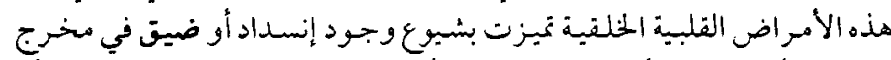

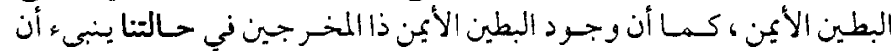

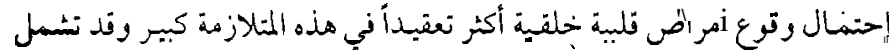

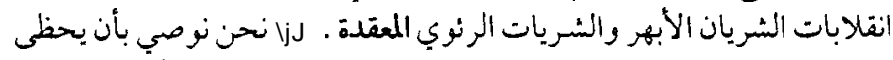

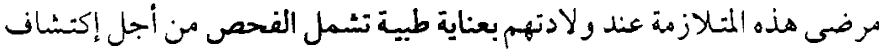

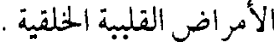

